\title{
Introduction to the Special Issue: 2016 Choice Symposium
}

\author{
Gerald Häubl $^{1}$ - Peter T. L. Popkowski Leszczyc ${ }^{1}$ \\ Published online: 1 March 2018 \\ (C) Springer Science+Business Media, LLC, part of Springer Nature 2018
}

This special issue features a collection of ten articles that were inspired by workshops at the tenth Triennial Invitational Choice Symposium hosted by the University of Alberta School of Business, held May 14-17, 2016, in Lake Louise, Canada.

The Triennial Choice Symposium provides a forum for indepth interaction among the world's preeminent scholars from various scientific disciplines in the domains of human choice behavior and decision-making. The format of the Symposium is such that it entails a number of parallel 3-day workshops (each with about 8-12 participants) on different themes related to decision-making and choice with the objective of facilitating discourse that will lead to advances both in our theoretical/substantive understanding of how people make choices and in the methods for studying choice behavior.

The 2016 Choice Symposium had a record number of 31 workshops. From these workshops, a set of ten papers emerged that were ultimately accepted for publication in this special issue after undergoing a peer-review process. Each of the papers originated during the discussions of one of the workshop groups during the Symposium at Lake Louise and was subsequently developed into a complete article with input and guidance from a team of expert reviewers. The articles featured in this special issue tend to be conceptual and integrative in nature. Many of them also provide somewhat of a roadmap for future research in a particular domain.

Gerald Häubl and Peter T.L. Popkowski Leszczyc

Special Issue Co-Editors

Articles in this Special Issue:

Gerald Häubl

gerald.haeubl@ualberta.ca

Peter T. L. Popkowski Leszczyc

ppopkows@ualberta.ca

1 School of Business, University of Alberta, Edmonton, AB T6G 2R6, Canada
Thomadsen et al. (2018) discuss how contexts, defined as any factors that may influence choices by altering the choice process, affect choices. They extend the range of context effects, focusing on the influence of social and situational factors on choice.

Lurie et al. (2018) examine the impact of mobile technology on consumer decision-making. They discuss the interactions between mobile ecosystems and the contexts in which mobile technology is used, and they identify important areas of future research.

André et al. (2018) address how consumers' well-being is affected by their sense of autonomy in decision-making. They focus on how new technologies influence consumers' perceptions of control over their choices and the subsequent impact on their well-being.

Albuquerque et al. (2018) provide a framework for studying the influence of children and parents' characteristics, as well as marketing efforts, on children's food purchases, and food consumption choices.

Dellaert et al. (2018) focus on incorporating individuals' use of multiple goals in econometric choice models. They conceptualize a framework and propose a process of individual decision-making when consumers pursue multiple goals.

Ascarza et al. (2018) provide an integrated framework for managing consumer retention. They discuss different metrics for managing retention and novel approaches applying machine-learning methods.

Aribarg et al. (2018) extend non-compensatory choice models by examining the issue of empirical identification for different types of data and identifying novel applications of such models.

Papatla et al. (2018) focus on the sharing economy and peer-to-peer trading facilitated by the internet, where consumers provide short-term rentals of durable assets to other consumers (e.g., accommodation rental via Air BNB and transportation services via Uber).

Rao et al. (2018) examine bundling for a variety of choice settings, focusing on three key dimensions: the number of product categories in a bundle, the party in the distribution 
system who constructs the bundle, and the time frame of the bundle choice decision.

Spann et al. (2018) examine customer-driven pricing mechanism, such as auctions and name-your-own-price markets, as well as pay-what-you-want pricing. They provide a taxonomy of participative pricing mechanisms and outline priority areas for future research on the topic.

Reviewers for this Special Issue:

Vic Adamowicz, University of Alberta

Anocha Aribarg, University of Michigan

Simona Botti, London Business School

Eric Bradlow, University of Pennsylvania

Rabikar Chatterjee, University of Pittsburgh

Hai Che, University of California Riverside

Yann Cornil, University of British Columbia

Benedict Dellaert, Erasmus University

Scott Fay, Syracuse University

Timothy Gilbride, University of Notre Dame
Ernan Haruvy, University of Texas at Dallas

Donna Hoffman, George Washington University

Joel Huber, Duke University

Jeffrey Inman, University of Pittsburgh

Katherine E. Loveland, HEC Montréal

Tina Lowrey, HEC Paris

Harmen Oppewal, Monash University

Purushottam Papatla, University of Wisconsin-Milwaukee

John Roberts, University of New South Wales

Itamar Simonson, Stanford University

Andrew Stephen, University of Oxford

Lin Tian, Shanghai University of Finance and Economics

Olivier Toubia, Columbia University

Luc R. Wathieu, Georgetown University

Russel Winer, New York University

Robert Zeithammer, UCLA 